\title{
The breeding biology of biotypes of the witches' broom pathogen of cocoa, Crinipellis perniciosa
}

\author{
G. W. GRIFFITH* \& J. N. HEDGER \\ Department of Biological Sciences, University College of Wales, Penglais, Aberystwyth, Dyfed SY23 3DA, U.K.
}

\begin{abstract}
Investigation of the breeding biology of the agaric Crinipellis perniciosa (causal agent of witches' broom disease of cocoa in South America) found that two distinct breeding strategies exist among the four known biotypes of the fungus, which are specific to cocoa (C-biotype), solanaceous hosts (S-biotype), Bixa orellana (B-biotype) and liana vines (L-biotype). The homomictic (primary homothallic) behaviour of the C-biotype was confirmed and single basidiospore isolates (SSIs) of the S-biotype and B-biotype were found to behave in a similar manner. The mycelia of most SSIs of the L-biotype did not bear clamp connections and pairings between sibling SSIs established that an outcrossing mechanism under the control of two unlinked mating type factors was operating (i.e. bifactorial heterothallism). These matings also suggested that one of the mating factors has a twogene structure. The occurrence of bi- and trinucleate basidiospores and SSIs bearing true or false clamp connections suggests that the L-biotype exhibits a limited degree of secondary homothallism.
\end{abstract}

Keywords: bifactorial heterothallism, cocoa, primary homothallism, tropical basidiomycete, witches' broom disease.

\section{Introduction}

The agaric Crinipellis perniciosa (Stahel) Sing., causal agent of witches' broom disease of cocoa (Theobroma cacao L.), is a well-documented and destructive pathogen, representing one of the major factors limiting cocoa production in South America and the Caribbean (Thorold, 1975). The fungus exhibits a hemibiotrophic life cycle (Hedger et al., 1989). Infection of meristematic cocoa tissues (shoots, flowers and pods) by basidiospores results in the growth of branched and swollen green brooms within which a non-clamped intercellular biotrophic mycelium proliferates (Wheeler, 1985). Death of the broom 4-6 weeks after infection is followed by invasion of the host tissues by a narrower, clamped mycelium similar to that found on agar media. The life cycle is completed by the production of basidiocarps on the surface of brooms 6-24 months later.

Baker \& Crowdy (1943) found the fungus to be homothallic, based on the observation that clamp connections are produced on the hyphae of single

*Correspondence: Memorial Building, School of Biological Sciences, University College of North Wales, Bangor, LL57 2UW, Wales basidiospore cultures. Delgado \& Cook (1976a) observed karyogamy in immature basidia and found that basidiospores are uninucleate and formed on basidia in tetrads. The fertility of single spore cultures was demonstrated by Purdy et al. (1983) who induced basidiocarps on mycelia derived from single spores. These lines of evidence suggest that the non-outcrossing breeding strategy adopted by $C$. perniciosa is homomixis (primary homothallism).

The breeding strategy adopted by a particular organism has far-reaching consequences for its population biology. For basidiomycete species which have no known anamorphic (asexual) means of spore production, a non-outcrossing breeding strategy disseminates the parental genotype and avoids the necessity for mating with a compatible primary mycelium (monokaryon) prior to basidiocarp formation. In the case of C. perniciosa, every successful infection of a cocoa meristem is potentially fertile, hence permitting more rapid and clonal spread of the fungus. $C$. perniciosa is known to produce arthroconidia in agar culture (Delgado \& Cook, 1976b) but these have not been observed in nature and have not been shown to infect cocoa tissues.

C. perniciosa was originally believed to be restricted to hosts belonging to two genera of the family Sterculi- 
aceae, namely Theobroma and Herrania (Baker \& Holliday, 1957). However, more recently the fungus has been reported on a wider range of unrelated hosts. We consider that evidence from morphological, cultural and plant inoculation studies suggests that these represent four discrete biotypes (Evans, 1977, 1978; Hedger et al., 1987; Bastos et al., 1988). The Solanum biotype (S-biotype) and the Bixa biotype (Bbiotype) cause witches' broom disease symptoms on a range of solanaceous hosts (Bastos \& Evans, 1985) and the shrub Bixa orellana (Bastos \& Andebrhan, 1986), respectively. Basidiocarps of $C$. perniciosa have also been found on both live and dead liana vines. There is no evidence that this liana biotype (L-biotype) is linked with any disease symptoms (Evans, 1978; Hedger et al., 1987) but Griffith (1989) has shown that the L-biotype in Ecuador is host specific and is associated with the liana Arrabidaea verrucosa (Bignoniaceae).

Here we report studies on the ontogeny and breeding behaviour of isolates of $C$. perniciosa from several locations in South America and representing the four known biotypes. The results are discussed with reference to the mycelial development of the fungus and to the possible evolution of the taxon.

\section{Materials and methods}

Mycelial cultures were obtained by plating out surface sterilized basidiocarp stipe tissues or samples of cocoa brooms and infected plant material on a selective medium (Griffith, 1989). This consisted of a basal Malt-Yeast Extract Agar [MYEA; $30 \mathrm{~g} / 1$ dark malt extract powder, $5 \mathrm{~g} / \mathrm{l}$ yeast extract, $15 \mathrm{~g} / \mathrm{l}$ agar (all from Lab M Ltd)], supplemented with an additional 15 $\mathrm{g} / \mathrm{l}$ agar (i.e. double-strength). After autoclaving (15 min, $15 \mathrm{psi}$ ), $10 \mathrm{ml} / \mathrm{l}$ of 1 per cent benomyl solution, $1 \mathrm{ml} / 13$ per cent of $o$-phenyl phenol and $10 \mathrm{ml} / \mathrm{l}$ of an antibiotic cocktail $(2 \mathrm{~g} / \mathrm{l}$ each of benzylpenicillin, streptomycin sulphate, ampicillin and chlorotetracyclin) were added. Basidiospores were obtained by inducing basidiocarp production on cocoa brooms and liana vines, using the method of Suarez (1977). In addition it proved possible to fruit mycelial cultures using the mycelial mat method of Purdy et al. (1983) and the bran-vermiculite method of Griffith \& Hedger (1993). In all cases, the induction of basidiocarp formation involved the simulation of tropical conditions by means of a mist chamber maintained at $27^{\circ} \mathrm{C}$ with a $12 \mathrm{~h}$ photoperiod (08.00-20.00 h). Deionized water was sprayed with a Defensor 500 humidifier for 6-8 h per day (Griffith, 1989).

Infected plant material and fungal cultures from Ecuador were collected by the authors, while brooms and cultures from other South American countries were kindly supplied by C. N. Bastos and T. Andebrhan (CEPLAC, Belem, Brazil), L. H. Purdy (University of Florida, Gainesville), E. A. Wyrley-Birch (ODA, Santa Cruz, Bolivia) and P. Hadley (University of Reading, England).

To obtain basidiospores, a freshly collected basidiocarp was suspended over a plate of 1 per cent water agar overnight at $25^{\circ} \mathrm{C}$ to deposit a spore print. Basidiospores from the print were streaked onto MYEA with a loop and after incubation at $25^{\circ} \mathrm{C}$ for 3-5 days, small, well-spaced colonies were picked off with a sterile needle, using a stereo microscope, and replated individually. These putative single spore isolates (SSIs) were numbered sequentially (e.g. LA 10.1 is the first SSI obtained from a basidiocarp of field isolate LA 10 etc.). Mycelial cultures were routinely maintained on MYEA at $25^{\circ} \mathrm{C}$.

To examine mating reactions, $5 \mathrm{~mm}$ diameter plugs of each of the two strains be be mated in each cross were placed $2 \mathrm{~cm}$ apart on a $9 \mathrm{~cm}$ petri dish of MYEA and incubated inverted at $25^{\circ} \mathrm{C}$. Plates were sealed with insulation tape to reduce water loss and the possibility of contamination. After 3 weeks incubation and subsequently at weekly intervals, $4 \mathrm{~mm}$ plugs were taken from the line of contact between the two colonies and from 1-2 cm either side of this line. These plugs were subcultured onto a fresh plate of MYEA while maintain their original orientation on the mating plate. After 3-5 days' incubation, $7 \mathrm{~mm}$ plugs were taken from the margins of these colonies and examined directly with a $40 \times$ objective. The presence or absence of clamp connections and the general morphology of the mycelium was recorded.

The method of Stephenson \& Gooday (1984) was used to examine the nuclear condition of hyphae and basidiospores. To obtain hyphae for staining, agar plugs of mycelia were incubated on glass slides in a Petri dish for 1-2 days, using damp filter paper to maintain high humidity. The inoculum plug was carefully removed and the hyphae which had grown onto the glass were stained with a drop of the fluorochrome DAPI (Sigma D-1388; $4 \mu \mathrm{g} / \mathrm{ml}$ solution in $100 \mathrm{~mm}$

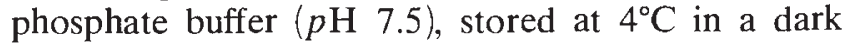
bottle). Basidiospores deposited from a fresh basidiocarp placed over a glass slide for $1 \mathrm{~h}$ were stained by adding a drop of the DAPI solution. In all cases a coverslip was placed over the tissue, which was then left at $4^{\circ} \mathrm{C}$ for $1 \mathrm{~h}$. Nuclei were observed by epifluorescence microscopy (Carl-Zeiss, filter no. 46-63-019901, excitation at $360 \mathrm{~nm}$ and fluorescence at 450 $\mathrm{nm}$ ) using a $63 \times$ oil-immersion objective. 


\section{Results}

\section{Spore germination and mycelial development}

Daily observations of young spore germlings from several representative $\mathrm{C}$-biotype isolates confirmed the findings of Delgado \& Cook (1976a). The germ tubes were initially swollen $(5-20 \mu \mathrm{m}$ diameter) until about $200 \mu \mathrm{m}$ in length. Between the second and seventh day after germination, cultures developed narrower hyphae (1-3 $\mu \mathrm{m}$ diameter) of similar diameter to those of mature (i.e. > 3-week-old) mycelium. Clamp connections were first observed between the seventh and 10th day after germination, usually at the centre of the colony. Clamps were initially sparse and unfused but, by the 10 th to 18 th day, fused clamps were visible throughout the mycelium. These results broadly confirm those of Hedger et al. (1987) who investigated the germination of mass spore cultures of the C-biotype and L-biotype. In the present study, however, the developmental changes were observed to occur more rapidly. This may have been due to increased spore density or less nutritious medium (Potato dextrose agar) used by Hedger et al.(1987).

The morphological development of germlings of S-biotype and B-biotype isolates was identical to that of the C-biotype. The growth of L-biotype basidiospores during the first week after germination followed the pattern described above. However, most single spore germlings of the L-biotype differed from those of the other biotypes in that subsequently no clamp connections were observed, even after 1-2 months incubation and repeated subculture. In a few cases persistent but unfused clamp connections were seen.

\section{Nuclear staining}

Examination of basidiospores from several isolates stained with the fluorochrome DAPI confirmed that most were uninucleate. However, a significant percentage were binucleate and in two cases trinucleate basidiospores were observed (Fig. 1, Table 1). There was no opportunity to examine basidiocarp hymenial tissues for the presence of two or three-spored basidia. It is possible that the bi- and trinucleate basidiospores were the result of post-meiotic nuclear division, although Kühner (1977) considered that such basidiospores generally arise through unequal nuclear segregation from bi- or trisporic basidia.

DAPI-staining also showed that hyphae bearing clamps were consistently binucleate in isolates of all biotypes, while the unclamped hyphae of L-biotype
Fig. 1 Bi- and trinucleate basidiospores of C. perniciosa stained with the fluorochrome DAPI (see text). Lightphase plates (a) and (c) correspond to the dark-phase plates (b) and (d), respectively. Note the binucleate basidiospore (centre field in Fig. 1b) from the L-biotype isolate SCL4 and the trinucleate basidiospore (centre field in Fig. 1d) from the Brazilian S-biotype isolate 314. Bar represents $20 \mu \mathrm{m}$.
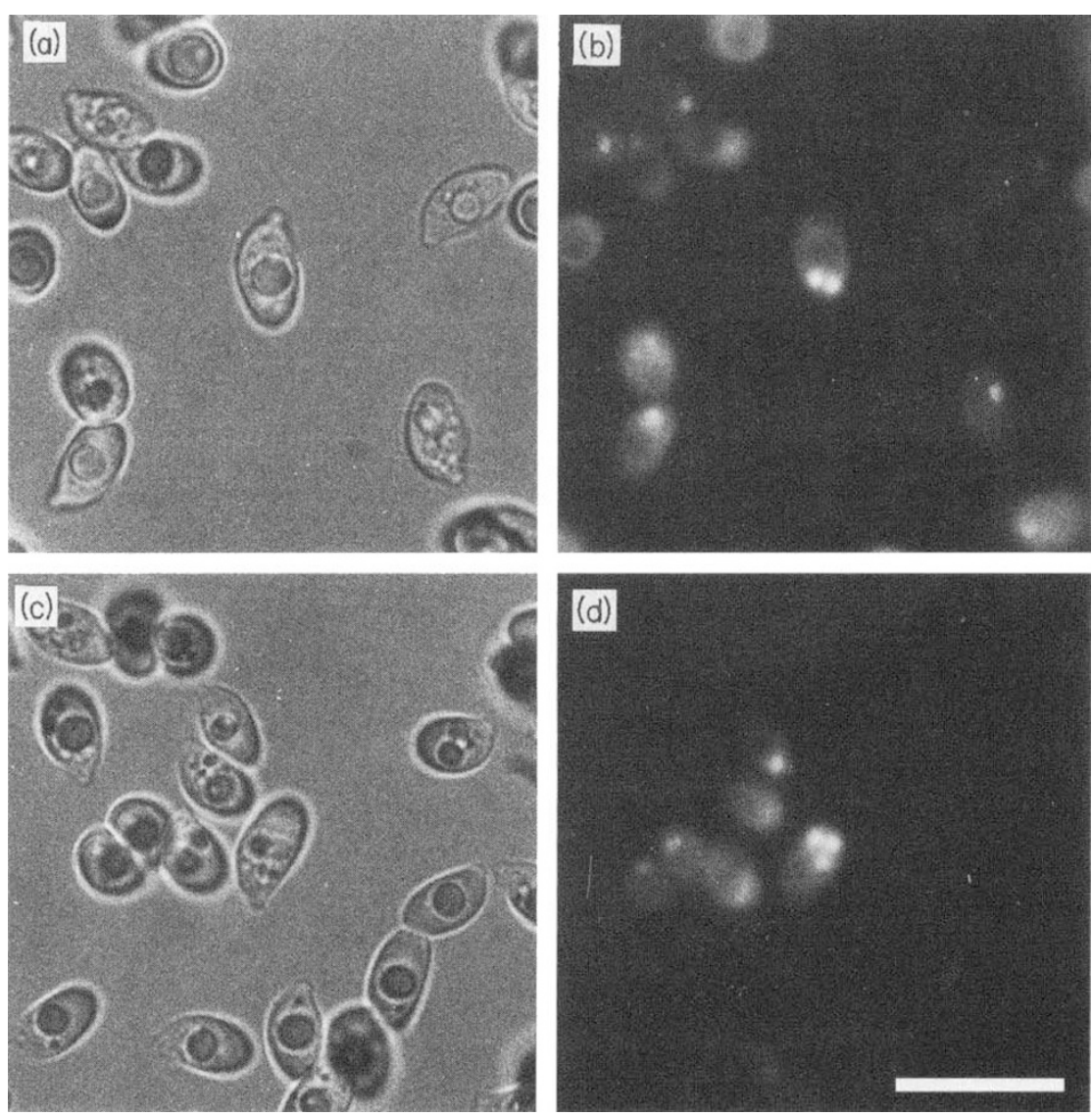
Table 1 The nuclear condition of basidiospores of biotypes of $C$. perniciosa as assessed by DAPI staining

\begin{tabular}{|c|c|c|c|c|c|c|}
\hline \multirow[b]{2}{*}{ Accession No. } & \multirow[b]{2}{*}{ Biotype } & \multirow[b]{2}{*}{ Origin $†$} & \multirow{2}{*}{$\begin{array}{l}\text { Method of } \ddagger \\
\text { basidiocarp production }\end{array}$} & \multicolumn{3}{|c|}{ Nuclear condition (\%) of basidiospores§ } \\
\hline & & & & Uninucleate & Binucleate & Trinucleate \\
\hline unk1 & Cocoa & $\mathrm{CE}$ & B & 99.1 & 0.9 & 0 \\
\hline unk2 & Cocoa & $\mathrm{CE}$ & B & 98.6 & 1.4 & 0 \\
\hline 226 & Cocoa & $\mathrm{CE}$ & V & 98.4 & 1.6 & 0 \\
\hline 405 & Cocoa & B & V & 99.2 & 0.8 & 0 \\
\hline 314 & Solanum & B & $\mathrm{V}$ & 92.5 & 7.0 & 0.5 \\
\hline SCL4 & Liana & $\mathrm{AE}$ & V & 95.2 & 4.8 & 0 \\
\hline SCFT & Liana & $\mathrm{AE}$ & V & 90.8 & 7.6 & 1.6 \\
\hline
\end{tabular}

†Origin of isolates: CE: Coastal Ecuador; B: Brazil; AE: Amazonian Ecuador.

$¥$ Basidiocarps were produced either on naturally infected cocoa brooms (B), as described by Suarez (1977) or from mycelial cultures grown on bran-vermiculite medium (V) (Griffith \& Hedger, 1993).

$\S 300$ DAPI-stained basidiospores from a single basidiocarp were examined in each case.

SSIs were uninucleate. Confirmation of the nuclear condition of clamped and unclamped SSIs was made by Nomarski interference microscopy.

\section{Gross morphology of cultures}

Sibling single spore cultures of the C-biotype, S-biotype and B-biotype were highly uniform in appearance and indistinguishable from parental cultures. In contrast, sibling single spore cultures of the L-biotype were heterogeneous with respect to growth rate and morphology (Fig. 2), and were generally slower growing and less fluffy than the parental mycelia. When spores of the L-biotype were spread over a plate of MYEA medium, complex crimson pigment patterns, presumably arising from the interaction of different spore germlings were observed after about 3 weeks (Griffith, 1989). No such antagonistic interactions occurred in mass spore cultures of the other biotypes.

\section{Sib matings of mycelia of the L-biotype}

The absence of clamp connections on hyphae of most single spore cultures of the L-biotype (Table 2) and their presence on mass spore cultures and mycelia derived from basidiocarp stipe tissues, suggested that the L-biotype might be outcrossing (i.e. heterothallic) and that mating between compatible unclamped, primary mycelia is a prerequisite for the formation of secondary clamped mycelia (Burnett, 1975). To test this hypothesis, sets of sibling single spore cultures were paired in all possible combinations. In the case of one isolate, SCFT, the results of initial pairings with 15 SSIs were used to choose six tester isolates for pairing with a further 41 SSIs. SSIs found to bear true or false clamp connections were not included in these pairings and their status is discussed below.

Matings were conducted with sets of sibling SSIs from a total of 20 basidiocarps collected at three sites in coastal Ecuador, one site in Amazonian Ecuador and also a single isolate from Brazil. The provenance of these basidiocarps is shown in Table 2 . Approximately 25 per cent of sib matings gave rise to mycelia bearing clamp connections. In a smaller number of cases false (i.e. unfused) clamp connections were seen. In Fig. 3, the results of three representative sib-matings are arranged on the hypothesis that mating compatibility in the L-biotype is under the control of two, unlinked mating factors, i.e. bifactorial or tetrapolar heterothallism (Burnett, 1975).

In other tetrapolar species, the two mating type factors are denoted $\mathrm{A}$ and $\mathrm{B}$, according to the morphogenetic events which they control. Hence the A factor controls nuclear pairing, clamp cell formation and synchronized nuclear division, while the $\mathrm{B}$ factor controls nuclear migration and clamp cell fusion (Casselton \& Economou, 1985). As the matings of the L-biotype appeared to operate in a similar manner, it was possible to identify some hemi-compatible (common-B factor) pairings from the distribution of false clamps. Most pairings between non-sib SSIs were compatible (data not shown), demonstrating that multiple alleles at both loci are present within L-biotype populations (Griffith, 1989).

A summary of the results of all the sib-matings is given in Table 3. The mating type specificity of one SSI from each set of siblings is arbitrarily given the mating genotype $A_{x} B_{x}$. Depending on their mating reaction with this SSI, the other sibling cultures were denoted $A_{x} B_{y}, A_{y} B_{x}$ or $A_{y} B_{y}$. A and $\mathrm{B}$ represent the two mating 


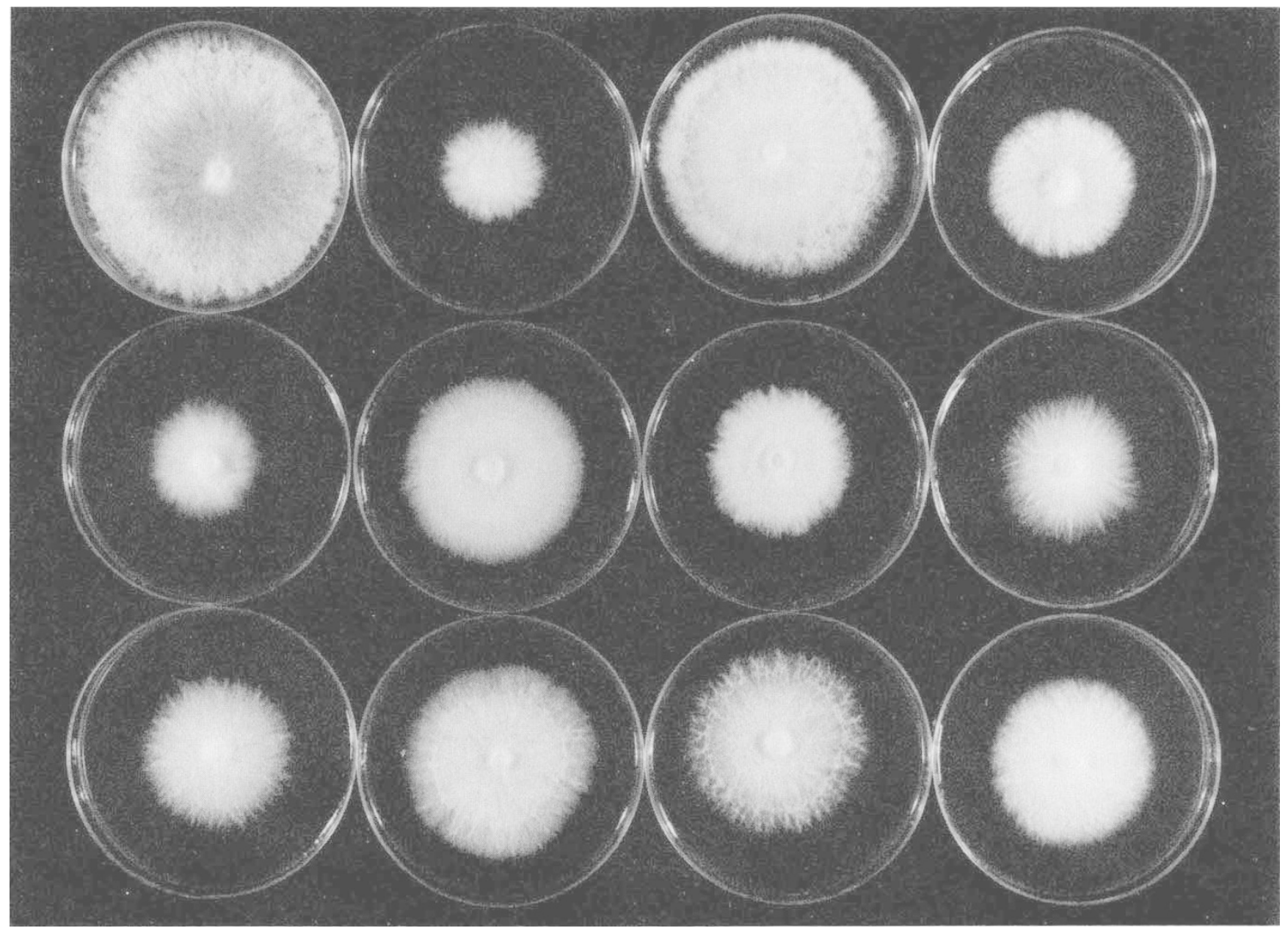

Fig. 2 Differences in gross morphology and radial growth rate between sibling single spore isolates (SSIs) from the L-biotype isolate, LZ1. A $7 \mathrm{~mm}$ agar plug of each isolate was inoculated centrally on MYEA (see text) in $9 \mathrm{~cm}$ Petri dishes and incubated at $25^{\circ} \mathrm{C}$ for 7 days. The parental isolate $\mathrm{LZ1}$ is in the top left corner and its progeny $\mathrm{LZ} 1.4,5,6,7,8,9,10,12,13,14$ and 15 are ordered from left to right and top to bottom. Note that the parental isolate is slightly fluffier and faster growing that its progeny.

type factors, while $x$ and $y$ represent the alternative alleles at these two loci in each set of siblings.

The number of SSIs in each set of pairings ranged from 3 to 56. In several sets, where only small numbers of sibling SSIs (i.e. $<10$ ) were isolated, fewer than the four possible combinations of mating type factors were identified. In four sets (LA10, LA46, LJ17 and SCL1A), no compatible or common-B matings were observed. In the case of LA46 and SCL1A, where 10 and 11 SSIs, respectively, were mated, unknown factors may have inhibited sib-mating or affected the distribution of mating factors among the basidiospore progeny. Deviations from normal Mendelian ratios among SSIs with respect to mating type factors and isozymes have also been reported in other basidiomycetes, for example Laccaria (Fries \& Mueller, 1984) and Pleurotus (May et al., 1988) species.

Although the results of the majority of sib-matings conformed to the expected pattern (e.g. isolate LA1;
Fig. 3a), pairings with some SSIs could not easily be interpreted. For example, SSIs LC3.12 (Fig. 3b), LZ1.22 and LZ1.31 (Fig. 3c) were compatible with about half of their sibs (i.e. both $A_{x} B_{x}$ and $A_{x} B_{y}$ ). Pairings with these 'aberrant' SSIs were repeated and it was confirmed that the clamps produced were actually fused. The gross morphology and nuclear condition of these SSIs and the secondary mycelia they produced was normal. Parag (1962) reported that common-A heterokaryons of Schizophyllum commune are sometimes stable but have a distinctive 'flat' morphology. When paired with compatible primary mycelia, nuclear migration is unilateral as acceptor migration is blocked. However, none of these features was observed in the 'aberrant' SSIs of C. perniciosa; all matings involving these SSIs were bilateral and morphologically normal.

The generation of new mating type specificities by intrafactor recombination has been observed in several basidiomycetes (Raper et al., 1958; Takemaru, 1961; 
Table 2 Presence or absence of true and false clamps in single basidiospore cultures of the liana biotype of C. perniciosa

\begin{tabular}{ccccccr}
\hline $\begin{array}{c}\text { Accession } \\
\text { No. }\end{array}$ & Origin & $\begin{array}{c}\text { Basidiocarp } \\
\text { source }\end{array}$ & $\begin{array}{c}\text { Fused } \\
\text { clamps }\end{array}$ & $\begin{array}{c}\text { False } \\
\text { clamps }\end{array}$ & $\begin{array}{c}\text { Clamps } \\
\text { absent }\end{array}$ & Total \\
\hline LA1 & Pichilingue & Field & 0 & 0 & 11 & 11 \\
LA10 & Pichilingue & Field & 3 & 0 & 5 & 8 \\
LA20 & Pichilingue & Field & 0 & 1 & 5 & 6 \\
LA21 & Pichilingue & Field & 2 & 0 & 5 & 7 \\
LA22 & Pichilingue & Field & 0 & 0 & 5 & 5 \\
LA41 & Pichilingue & Field & 5 & 0 & 6 & 11 \\
LA43 & Pichilingue & Field & 0 & 0 & 9 & 9 \\
LA46 & Pichilingue & Field & 1 & 0 & 10 & 11 \\
LC1 & Pichilingue & Field & 0 & 1 & 11 & 12 \\
LC3 & Pichilingue & Bran-vermiculite & 2 & 0 & 18 & 20 \\
LZ1 & Pichilingue & Liana & 4 & 0 & 29 & 33 \\
LJ11 & Jauneche & Field & 2 & 0 & 6 & 8 \\
LJ14 & Jauneche & Field & 1 & 0 & 8 & 9 \\
LJ15 & Jauneche & Field & 0 & 0 & 6 & 6 \\
LJ17 & Jauneche & Field & 2 & 0 & 3 & 5 \\
SCL1A & San Carlos & Bran-vermiculite & 3 & 0 & 17 & 20 \\
SCL2 & San Carlos & Bran-vermiculite & 3 & 2 & 15 & 20 \\
SCL4 & San Carlos & Bran-vermiculite & 5 & 2 & 18 & 25 \\
SCFT & San Carlos & Bran-vermiculite & 6 & 3 & 56 & 65 \\
450 & Brazil & Bran-vermiculite & 9 & 3 & 13 & 25 \\
\hline
\end{tabular}

Studies were made of single basidiospore isolates originating from four sites, namely Coastal Ecuador: (1) Pichilingue and (2) Jauneche, both in Los Rios Province, Amazonian Ecuador: (3) San Carlos, Napo Province and Brazil: (4) Manaus, Amazonas Province.

The single basidiospore cultures were obtained by spore fall from basidiocarps.

These were: (1) collected in the field by the authors, (2) from naturally infected liana tissue which was induced to fruit in a mist chamber, or (3) from mycelial cultures inoculated onto bran-vermiculite medium and placed in a mist chamber.

The Brazilian isolate (450) was supplied by Dr Cleber Bastos, CEPLAC, Belem, Brazil. Full details of the origin of the parental cultures are given in Griffith (1989).

Day, 1963; Eugenio \& Anderson, 1968) and is predicted to be widespread among bifactorial species (Raper \& Flexer, 1971). The present data are consistent with the interpretation that $C$. perniciosa has a B factor composed of two linked loci (i.e. $\mathrm{B} \alpha$ and $\mathrm{B} \beta$ ) and that recombination between these loci gives rise to new $B$ factor specificities (i.e. recombination between $B_{x}$ and $B_{y}$ gives rise to factors $B_{z}$ and $B_{a}$ ). However, only one of the two possible recombinant alleles was detected in these pairings and no evidenc of A factor recombination was found. Pairing experiments with larger sets of SSIs may permit identification of the full range of putative recombinant mating factor specificities.

The overall frequency of putative intrafactor recombination was 6 per cent, which is within the range observed in studies of other species (Koltin et al., 1972). The level of putative intrafactor recombination among the progeny of SCFT and SCL2 was 10 per cent ( 6 of 56$)$ and 14 per cent ( 2 of 14 ), respectively, while no recombinants were observed in several other sib-matings. Although sampling error may account for these differences, it is possible that, as in S. commune, the frequency of mating type factor recombination may be affected by genetic and environmental factors (Schaap \& Simchen, 1971).

Confirmation that B factor recombination occurs in $C$. perniciosa could be obtained by back-mating the putatively recombinant SSIs with SSIs containing the parental mating type factors. Intrafactor recombination should be absent among the progeny of these crosses as all would have the same allele at one or both of the B factor loci. The possibility that the 'aberrant' SSIs were the result of mutation in the $B$ factor cannot at present be ruled out. $B_{\text {mut }}$ mutants in which the $B$ factor is partially or totally inactivated are normal in appear- 
a) LA 1

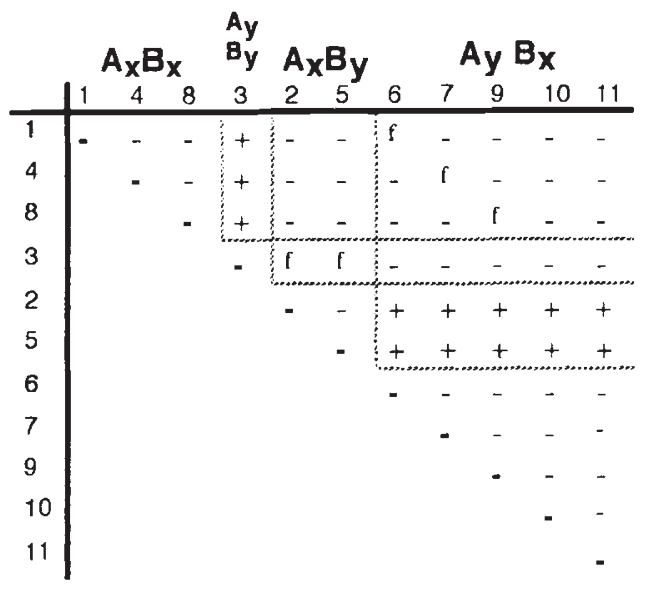

b) LC3

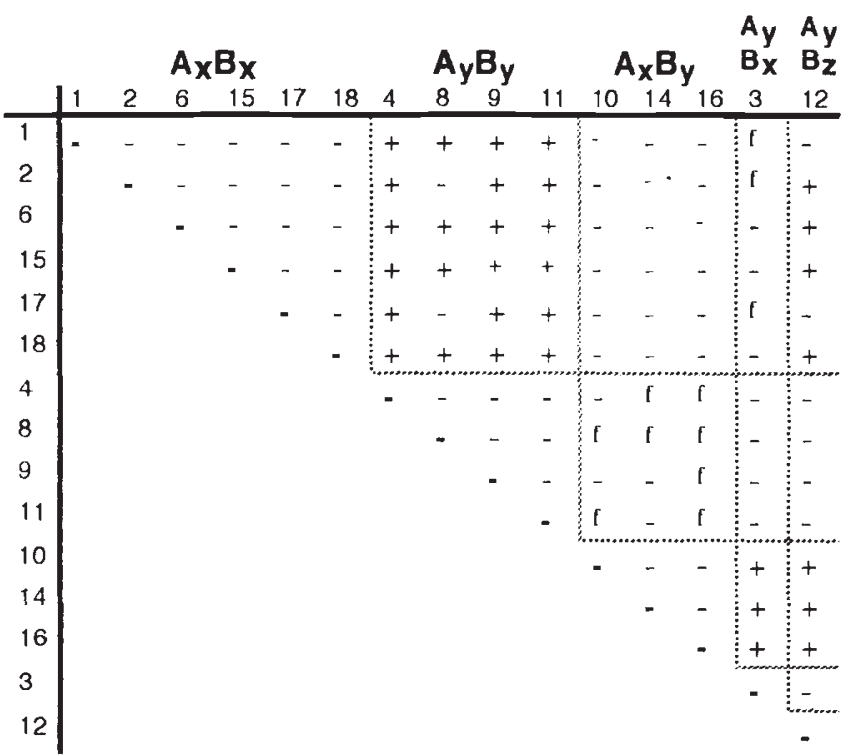

c) LZ1

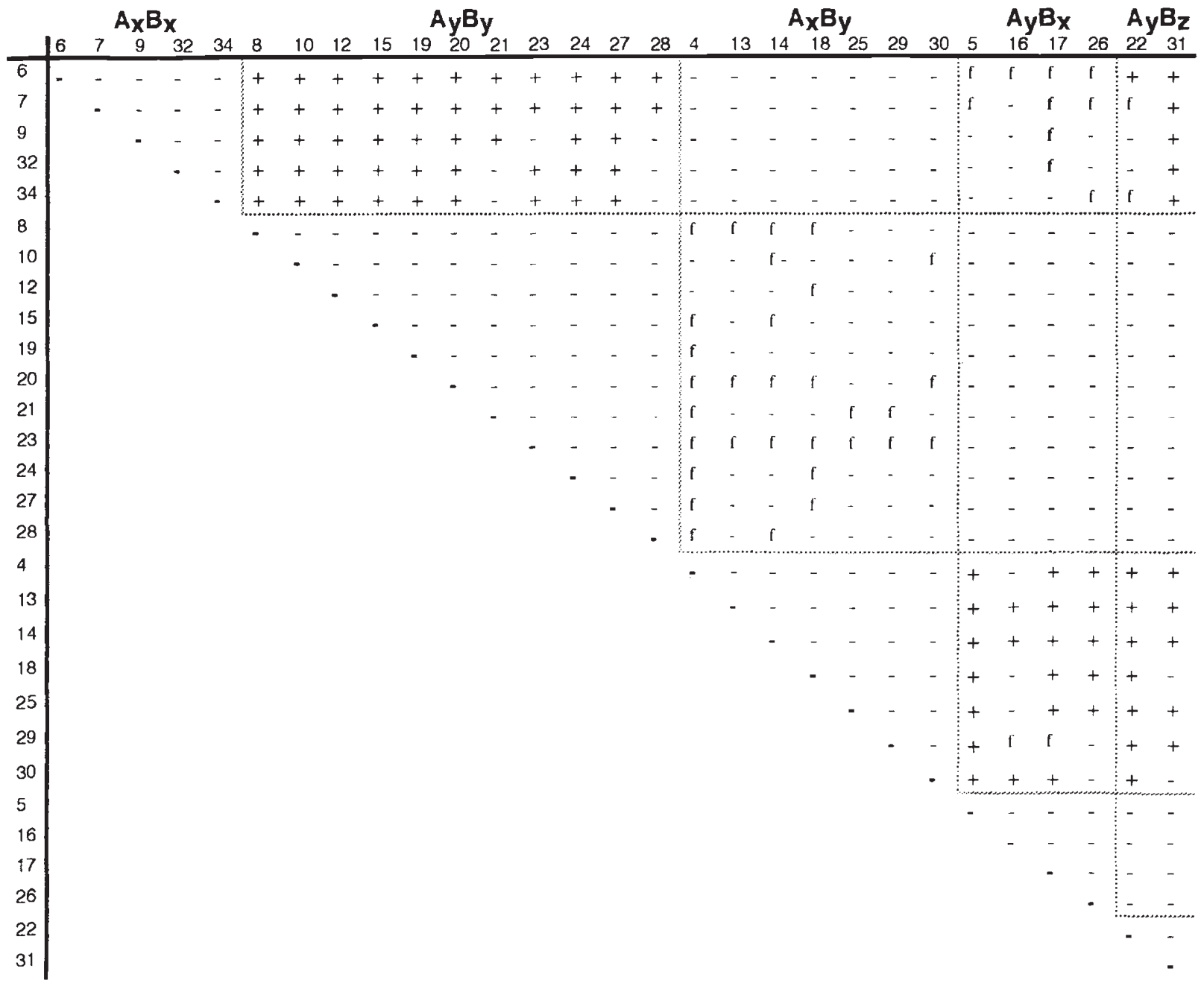

Fig. 3 Sibling single basidiospore isolates which did not bear clamp connections were paired in all combinations on Malt-Yeast Extract Medium and subcultures from mating plates examined for the presence/absence of clamp connections after 4 weeks growth, as described in the text. + = compatible pairing, fused clamp connections observed; - = incompatible pairing, no clamp connections observed; $f=$ hemi-compatible pairing, unfused clamp connections observed, indicative of some but not all common-B factor matings. Dotted lines are used to group SSIs showing the same mating type specificities. The mating factor genotypes $\left(A_{x} B_{x}\right.$ etc.), according to our interpretation of the data, are shown for each set. 
Table 3 Summarized results of sib-mating between primary mycelia of the L-biotype of $C$. perniciosa

\begin{tabular}{|c|c|c|c|c|c|c|}
\hline $\begin{array}{l}\text { Accession } \\
\text { No. }\end{array}$ & $A_{x} B_{x} \dagger$ & $A_{y} B_{y}$ & $A_{x} B_{y}$ & $A_{y} B_{x}$ & Other $\ddagger$ & $\begin{array}{l}\text { Total no. } \\
\text { of SSIs }\end{array}$ \\
\hline LA1 $\S$ & 3 & 1 & 2 & 5 & 0 & 11 \\
\hline LA10 & n.d.t† & n.d. & n.d. & n.d. & n.d. & 4 \\
\hline LA20 & 4 & 1 & 0 & 0 & 0 & 5 \\
\hline LA2 1 & 1 & 2 & 0 & 1 & 1 & 5 \\
\hline $\mathrm{LA} 22$ & 3 & 1 & 0 & 0 & 0 & 4 \\
\hline LA4 1 & 0 & $(--6$ & $--\mid \neq \div$ & 0 & 0 & 6 \\
\hline LA43 & 3 & 1 & 2 & 2 & 1 & 9 \\
\hline LA46 & n.d. & n.d. & n.d. & n.d. & n.d. & 10 \\
\hline $\mathrm{LC} 1$ & 4 & 3 & 2 & 0 & 1 & 10 \\
\hline LC3§ & 6 & 4 & 3 & 1 & 1 & 15 \\
\hline LZ1§ & 5 & 11 & 7 & 4 & 2 & 29 \\
\hline LJ1 1 & 2 & 2 & 1 & 1 & 0 & 6 \\
\hline LJ14 & 3 & 4 & $(--1)$ & $--)$ & 0 & 8 \\
\hline LJ15 & 3 & 1 & $(--2$ & --1 & 0 & 5 \\
\hline LJ17 & n.d. & n.d. & n.d. & n.d. & n.d. & 3 \\
\hline SCL1A & n.d. & n.d. & n.d. & n.d. & n.d. & 11 \\
\hline SCL2 & 3 & 5 & 1 & 3 & 2 & 14 \\
\hline SCL4 & 2 & 2 & 2 & 4 & 0 & 10 \\
\hline SCFT & 19 & 8 & 14 & 9 & $5 \S \S$ & 56 \\
\hline 450 & 3 & 1 & 6 & 3 & 0 & 13 \\
\hline
\end{tabular}

$†$ The mating type specificity of the SSI (Single Spore Isolate) with the lowest accession number in each set (e.g. LAl.1, see Fig. 3) was arbitrarily designated the genotype $A_{x} B_{x}$. The genotype of other SSIs were assigned according to this. The distribution of false clamps was used to identify common-B factor pairings.

$\ddagger$ The results in this column represent single basidiospore isolates (SSIs) which do not conform to a simplistic analysis of mating factor genotype and which may represent examples of $\mathrm{B}$ factor recombination (i.e. $A_{x} B_{z}$ or $A_{y} B_{z}$ ).

§Full results for these sib-matings are shown in Fig. 3 . $\dagger \dagger$ In four sets of SSIs, no compatible or hemi-compatible mating reactions were detected. The mating type specificities of SSIs could not be determined (= n.d.).

$\ddagger \ddagger$ In three cases fewer than four mating factor genotypes were identified. In these cases parentheses are used to designate the possible mating type specificities.

$\S \S$ Only in the case of SCFT were two putative recombinant genotypes identified (i.e. four assigned the genotype $A_{x} B_{z}$ and one $A_{y} B_{2}$ ).

ance and mating behaviour in Coprinus cinereus (Casselton \& Economou, 1985), although not in $S$. commune (Koltin et al., 1967). However, the independent occurrence of such mutations at the frequency recorded here is highly unlikely.

A limited number of pairings were repeatably incompatible and did not conform to the interpretation described above (e.g. LC3.2 $\times$ LC3.8, Fig. 3b). Similarly, false clamps were not observed in all pairings which were subsequently interpreted as involving
common-B factors. Other investigations of basidiomycete outcrossing mechanisms have recorded similar observations e.g. (Macrae, 1967; Ginns 1974). Most common-B heterokaryons were found to be unstable and formed sectors corresponding to the component primary mycelia when subcultured. However, a few common-B heterokaryons bearing false clamps remained stable after repeated subculturing (data not shown). It is possible that the stability of heterokaryotic mycelia formed during the initial stages of mating was influenced by genetic factors unlinked to mating factors.

The dynamics of dikaryon formation during compatible matings suggested that the secondary mycelium propagated from the junction zone by hyphal growth, rather than by the migration of nuclei through preexisting hyphae, as observed in several other bifactorial species (Snider \& Raper, 1958; Bistis, 1970). Pairings between secondary and primary mycelia, i.e. di-mon matings or the 'Buller' phenomenon; (Raper, 1966; Coates \& Rayner, 1985) never gave rise to a new secondary mycelium, suggesting that mating in the L-biotype only occurs between primary mycelia. The failure of such pairings may be due to the restricted nature of nuclear migration in C. perniciosa.

In a number of species, which like the L-biotype exhibit 'normal' development (Boidin, 1971), it is possible to differentiate mating reactions on the basis of changes in gross morphology (Martin \& Gilbertson, 1973; Ullrich \& Anderson, 1978; Moore, 1985). Zones of antagonism, sometimes involving pigment production, were frequently observed in L-biotype sibmatings, although it was not possible to predict reliably the result of pairings without microscopic examination. In compatible pairings, these zones tended to become overgrown by the fluffier secondary mycelium while the most distinct barrages were produced in common-B pairings. The intensity of the zones of antagonism was greater for some sets of sibling SSIs (e.g. SCFT) than others (e.g. LA1).

\section{Discussion}

\section{Homomixis in the C-biotype of $\mathrm{C}$. perniciosa}

The structure of populations of the C-biotype has been investigated by Griffith (1989) and Wheeler \& Mepsted (1982, 1984). Their results demonstrated the occurrence of geographically widespread clones, as assessed by somatic compatibility reactions, and is suggestive of a non-outcrossing breeding strategy in this biotype.

In the present study, it was found that basidiospores of the C-biotype are mostly uninucleate and that sibling SSIs of the C-biotype were morphologically identical. 
This is consistent with the results of previous investigations of meiosis (Delgado \& Cook, 1976b) and basidiocarp production (Purdy et al., 1983) in the C-biotype. Although the possibility that the basidiospores are diploid has not been ruled out, the evidence that the C-biotype of $C$. perniciosa is homomictic is, nevertheless, convincing. Meiosis has not been examined in the S-biotype and B-biotype but the evidence presented here suggests that these biotypes are probably also homomictic.

It has been estimated that about 10 per cent of basidiomycetes species are non-outcrossing (Whitehouse, 1949), although some outcrossing species are capable of producing asexual spores (Kühner, 1977). Of these non-outcrossing species, most are known to be either homoheteromictic (amphithallic or secondary homothallic) or amictic/apomictic with incomplete sexual progression (Burnett, 1975; Kühner, 1977). True homomixis (primary or homo-dikaryotic homothallism) is rare and Lemke (1969) has estimated that only 1 per cent of basidiomycete species exhibit this type of breeding strategy. Among the few other species in which homomixis has been demonstrated, with any degree of certainty, are Coprinus patouillardii (Bayman \& Collins, 1990), Coprinus sterquilinus Fr. (Harder, 1926), Heterobasidion annosum (Chase et al., 1985) and Sistotrema brinkmannii (Lemke, 1969). Several members of the genus Stereum are non-outcrossing (Ainsworth, 1987) but as convincing evidence of meiosis in the basidia of Stereum sanguinolentum is lacking, it is possible that these species are actually apomictic (Rayner \& Turton, 1982).

In outcrossing species, the process of somatosexual differentiation, leading to the development of the secondary mycelium, is prevented until heterozygosity at the mating type loci is achieved by compatible mating (Burnett, 1975). However, in homomictic species, this process is constitutively initiated soon after basidiospore germination and is completed within 5-10 days and 7-10 days in S. brinkmannii and $H$. annosum, respectively (Ullrich \& Raper, 1975; Chase et al., 1985). A comparable length of time elapsed between spore germination and the stabilization of the homodikaryotic secondary mycelia in the C-biotype.

It has been suggested that mating between the primary mycelia of outcrossing species is permitted by the suppression of the somatic incompatibility mechanisms which prevent successful hyphal fusions between secondary mycelia (Coates et al., 1981). It is possible that some form of heterokaryosis can occur between genetically distinct mycelia of homomictic species during the short period of time when the young mycelium is undergoing autodikaryosis. However, it is not clear whether stabilization of the phenotypically secondary mycelium is preceded by the processes of acceptor and access migration, as in outcrossing species (Rayner et al., 1984).

The life cycle of the C-biotype of C. perniciosa (and the S-biotype and B-biotype) in nature involves a prolonged biotrophic phase (usually 4-6 weeks) after basidiospore germination (Wheeler, 1985). Multiple infection of host meristems by genetically distinct basidiospores may provide an opportunity for heterokaryosis between the phenotypically primary (i.e. unclamped and uninucleate) biotrophic mycelia. If such heterokaryotic mycelia arise during the biotrophic phase, they may form stable heterodikaryons when the host tissues die and the fungus enters the saprotrophic growth phase.

\section{Outcrossing in the L-biotype of $\mathrm{C}$. perniciosa}

Our results demonstrate that the outcrossing mechanism of the L-biotype of $C$. perniciosa is essentially the same as that of $S$. commune and $C$. cinereus (Raper, 1966; Casselton \& Economou, 1985). Genetical control of secondary mycelium development is bifactorial, multiallelic and there was evidence that at least one of these mating factors may have a two-locus structure. Two-locus mating type factors permit both fine control of inbreeding bias, while maintaining a high outbreeding potential (Stamberg \& Koltin, 1973). Recent studies have indicated that the molecular structure of basidiomycete mating factors is more complex than was previously suggested by genetic studies (Kües et al., 1992). However, a model proposed by Kües \& Casselton (1992) is consistent with both molecular and genetic evidence obtained from several bifactorial basidiomycete species, suggesting that similar genetic mechanisms control somatosexual development among diverse members of this taxon, possibly including the L-biotype of $C$. perniciosa.

The occurrence of bi- and trinucleate basidiospores is consistent with the observation that a significant proportion of L-biotype SSIs were found to bear true or false clamps. In Rhizoctonia solani, two to five-spored basidia are common and up to 33 per cent of basidiospores are binucleate (Anderson, 1984). Kerrigan \& Ross (1987) have shown that the average number of spores per basidium of the bifactorial Agaricus subrufescens is often significantly less than four. They postulated that partial homoheteromictic (secondary homothallic) behaviour provides a degree of reproductive assurance, for instance during the colonization of substrates where the probability of encountering compatible primary mycelia is low. It is therefore possible that the L-biotype may also be able to achieve inbreeding by the production of binucleate, potentially selffertile basidiospores. 
The fact that the L-biotype is host specific (Griffith, 1989) suggests that infection of $A$. verrucosa meristems by basidiospores may represent an important mechanism for the establishment of new mycelial systems. As the development of a secondary mycelium is a prerequisite for basidiocarp production, the dynamics of the mating processes could have important consequences for the biology of the fungus. The level of intrafactor recombination (possibly also involving the A factor) and the frequency of occurrence of multinucleate basidiospores will influence the degree of inbreeding in populations of the L-biotype and may have implications for gene flow within populations (Kirby, 1984).

\section{Evolutionary relationships between the biotypes of $\mathrm{C}$. perniciosa}

The preponderance of diaphoromixis (heterothallism) among the basidiomycetes (Whitehouse, 1949) is considered to be an indication that this is an ancestral feature and that non-outcrossing strategies have evolved secondarily (Raper \& Flexer, 1971; Koltin et al., 1972). Most non-outcrossing basidiomycetes are closely related to, or taxonomically conspecific with, outcrossing species (Lemke, 1969; Kemp, 1975; David \& Déquatre, 1984), suggesting that comparatively small genetical changes are involved in such breeding strategy changes (Brasier, 1987; Collins, 1987). Ainsworth (1987) reported the occurrence of outcrossing and non-outcrossing breeding behaviour within isolates obtained from both sympatric and allopatric populations of several Stereum species. He found that the adoption of a non-outcrossing breeding strategy could result in effective genetic isolation, possibly permitting the maintenance of an adaptive genotype by clonal reproduction.

We have shown that homomictic and bifactorial outcrossing populations exist within the biotypes of $C$. perniciosa and it is possible that homomixis may have evolved from an ancestral bifactorial system. The evolution of homomixis in $C$. perniciosa by the coincident inactivation of both of the mating type factors of a bifactorial ancestor, by deletion or mutation, is highly improbable (Koltin, 1978). However, the possibility that unifactorial populations of $C$. perniciosa also exist and that homomictic populations may have evolved from these (as suggested for S. brinkmannii; Lemke, 1969; Ullrich \& Raper, 1975), cannot be ruled out.

An alternative explanation is afforded by the work of Lanquetin \& Boidin (1983) who found that the monosporous progeny of some hybrids between the two bifactorial species, Dichostereum durum and $D$. sordulentum were non-outcrossing. Clamp connections formed on these mycelia only after several weeks, suggesting that secondary mycelium formation was impeded, compared with other naturally occurring homomictic species. Some of the hybrid progeny of nutritionally forced pairings between homomictic and unifactorial isolates of $S$. brinkmannii also showed similarly delayed clamp connection formation (Ullrich \& Raper, 1975). This may be an indication that there is partial expression of mating type functions and a resulting delay in secondary mycelium formation. The evolution of homomixis in $C$. perniciosa may have occurred by a similar hybridization event, possibly involving hitherto undiscovered biotypes of the species.

\section{Acknowledgements}

The authors would like to express their gratitude to the staff of INIAP in Ecuador, particularly Dr Alan Maddison and Ing. Jaime Aragundi for their cooperation. Plant and fungal material was imported to Wales under licence (Ministry of Agriculture no. PHF 46138). Financial support from the S.E.R.C. and the award of a Wain Fellowship to G.W.G. is gratefully acknowledged.

\section{References}

AINSWORTH, A. M. 1987. Occurrence and interactions of outcrossing and non-outcrossing populations in Stereum, Phanerochaete and Coniophora. In: Rayner, A. D. M., Brasier, C. M. and Moore, D. (eds) Evolutionary Biology of the Fungi, British Mycological Society Symposium, vol. 12, pp. 286-299. Cambridge University Press, Cambridge, U.K.

ANDERSON, N. A. 1984. Variation and heterokaryosis in Rhizoctonia solani. In: Jennings, D. H. and Rayner, A. D. M. (eds) Ecology and Physiology of the Fungal Mycelium, British Mycological Society Symposium, vol. 8, pp. 367-382. Cambridge University Press, Cambridge, U.K.

BAKER, R. E. D. AND CROWDY, S. H. 1943. Studies in the witches' broom disease of cocoa caused by Marasmius perniciosus Stahel. Part 1. Introduction, symptoms and aetiology. Mem. Imp. Coll. Trop. Agr., Trinidad, 7, 1-28.

BAKER, R. E. D. AND HOLLIDAY, P. 1957. Witches' broom disease of cocoa (Marasmius perniciosus Stahel). Phytopathological Papers. Kew, U.K., 2, Commonwealth Mycological Institute.

BASTOS, C. N. AND ANDEBRHAN, T. 1986. Urucu (Bixa orellana): Nova espécie hospedera da vassoura de bruxa (Crinipellis perniciosa) do cacueiro. Fitopatol. Brasil., 11, 963-965 (in Portuguese).

BASTOS, C. N., ANDEBRHAN, T. AND DE ALMEIDA, L. C. 1988. Comparação morfólogica de isolados de Crinipellis perniciosa. Fitopatol. Brasil., 13, 202-206 (in Portuguese).

BASTOS, C. N. AND EVANS, H. C. 1985. A new pathotype of Crinipellis perniciosa (witches' broom disease) on solanaceous hosts. Plant Pathology, 34, 306-312. 
BAYMAN, P. AND COLLINS, O. R. 1990. Meiosis and premeiotic DNA synthesis in a homothallic Coprinus. Mycologia, 82, 170-174.

BISTIS, G. N. 1970. Dikaryotisation in Clitocybe truncicola. Mycologia, 62, 911-924.

Boidin, J. 1971. Nuclear behaviour in the mycelium and the evolution of the basidiomycetes. In: Petersen, R. H. (ed.) Evolution in the Higher Basidiomycetes, pp. 129-148. University of Tennessee Press, Knoxville, U.S.A.

BRASIER, C. M. 1987. The dynamics of fungal speciation. In: Rayner, A. D. M., Brasier, C. M. and Moore, D. (eds) Evolutionary Biology of the Fungi, British Mycological Society Symposium, vol. 12, pp. 231-260. Cambridge University Press, London, U.K.

BURNETT, J. H. 1975. Mycogenetics. John Wiley and Sons, London, U.K.

CASSELTON, L. A. AND ECONOMOU, A. 1985. Dikaryon formation. In: Moore, D., Casselton, L. A., Wood, D. A. and Frankland, J. C. (eds) Developmental Biology of Higher Fungi, British Mycological Society Symposium, vol. 10, pp. 213-229. Cambridge University Press. Cambridge, U.K.

CHASE, T. E., ULLRICH, R. C. AND KORHONEN, K. 1985. Homothallic isolates of Heterobasidion annosum. Mycologia, 77, 975-977.

COATES, D. AND RAYNER, A. D. M. 1985. Heterokaryon-homokaryon interactions in Stereum hirsutum. Trans, Brit. Mycol. Soc., 84, 637-645.

COATES, D., RAYNER, A. D. M. AND TODD, N. K. 1981. Mating behaviour, mycelial antagonism and the establishment of individuals in Stereum hirsutum. Trans. Br. Mycol. Soc., 76, 41-51.

COLLINS, o. R. 1987. Reproductive biology and speciation in Myxomycetes. In: Rayner, A. D. M., Brasier, C. M. and Moore, D. (eds) Evolutionary Biology of the Fungi, British Mycological Society Symposium, vol. 12, pp. 271--283. Cambridge University Press, Cambridge, U.K.

DAvid, A. AND DÉquatre, B. 1984. Deux ultraspecies: Antrodia malicola (Berk. et Curt.) Donk et (Berk. et Br.) Donk (Basidiomycete, Aphyllophorales). Cryptogamie, Mycologie, 5, 293-300.

DAY, P. R. 1963. The structure of the A mating type factor in Coprinus lagopus: wild alleles. Genet. Res., , 4, 323-325.

DELGADO, J. C. AND COOK, A. A. 1976a. Nuclear condition of the basidia, basidiospores and mycelia of Marasmius perniciosus. Can. J. Bot., 54, 66-72.

DELgado, J. C. AND COOK, A. A. 1976b. Arthroconidia formation in cultures of Marasmius perniciosus. Phytopathology, 66, 717-718

EUGENIO, C. S. AND ANDERSON, N. A. 1968. The genetics and cultivation of Pleurotus ostreatus. Mycologia, $\mathbf{6 0}$, 627-634.

EVANS, н. C. 1977. The occurrence of pathotypes of Crinipellis perniciosa (Stahel) Singer in the tropical forest ecosystem. Proceedings of the Sixth International Cocoa Research Conference, 1977, Caracas, Venezuela, pp. 166-170. Cocoa Producers Alliance, Lagos, Nigeria.

EVANS, H. C. 1978. Witches' broom disease of cocoa (Crinipellis perniciosa) in Ecuador. 1. The fungus. Ann. Appl. Biol., 89, 185-192.
FRIES, N. AND MUELLER, G. M. 1984. Incompatibility systems, cultural features and species circumscriptions in the ectomycorrhizal genus Laccaria (Agaricales). Mycologia, 76, 633-642.

GINNS, J. H. 1974. Secondary homothallic Hymenomycetes: several examples of bipolarity are reinterpreted as being tetrapolar. Can. J. Bot., 52, 2097-2110.

GRIFFITH, G. W. 1989. Population structure of the cocoa pathogen Crinipellis perniciosa (Stahel) Sing. Ph.D. Thesis, University of Wales.

GRIFFITH, G. W. AND HEDGER, J. N. 1993. A novel method for producing basidiocarps of the cocoa pathogen Crinipellis perniciosa using a bran-vermiculite medium. Netherlands J. Plant Pathol., 99, 227-230.

HARDER, R. 1926. Mikrurgische untersuchungen über die geschlechtliche tendenz der Paarkerne des homothallischen Coprinus sterquilinus Fr. Planta, 2, 446-453 (in German).

HEDGER, J. N., GRIFFITH, G. W., BROWNLEE, H. E., MCEUEN, A., BRAVO, E. AND SCOTT, I. M. 1989. Witches' brooms and cocoa. J. Agr. Soc., Univ. Coll. Wales, 69, 164-183.

HEDGER, J. N., PICKERING, v. AND ARAGUNDI, J. A. 1987. Variability of populations of the witches' broom disease of cocoa (Crinipellis perniciosa). Trans. Br. Mycol. Soc., 88, 533-546.

KEMP, R. F. O. 1975. Breeding biology of Coprinus species in the section Lanatuli. Trans. Br. Mycol. Soc., 65, 375-388.

KERRIGAN, R. W. AND ROSS, I. K. 1987. Dynamic aspects of basidiospore number in Agaricus. Mycologia, 79 , 204-215

KIRBY, G. C. 1984. Breeding systems and heterozygosity in populations of tetrad forming fungi. Heredity, 52, 35-41.

KOLTIN, Y. 1978. Genetic structure of incompatibility factors: the ABC of sex. In: Schwalb, M. N. and Miles, P. G. (eds) Genetics and Morphogenesis in the Basidiomycetes, pp. 31-45. Academic Press, New York, U.S.A.

KOLTIN, Y., RAPER, J. R. AND SIMCHEN, G. 1967. The genetic structure of the incompatibility factors of Schizophyllum commune: the B factor. Proc. Natl. Acad. Sci. U.S.A., 57, $55-62$

KOLTIN, Y., STAMBERG, 3 . AND LEMKE, P. A. 1972. Genetic structure and evolution of the incompatibility factors in higher fungi. Bacteriol. Rev., 36, 156-171.

KÜES, U. AND CASSELTON, L. A. 1992. Homeodomains and regulation of sexual development in basidiomycetes. Trends in Genetics, 8, 154-155.

KÜES, U., RICHARDSON, W. V. J., TYMON, A. M., MUTASA, E. S., GOTTGENS, B., GAUBATZ, S., GREGORIADES, A. AND CASSELTON, L. A. 1992. The combination of dissimilar alleles of the $\mathrm{A} \alpha$ and $\mathrm{A} \beta$ gene complexes, whose proteins contain homeodomain motifs, determines sexual development in the mushroom Coprinus cinereus. Genes Devel., 6, 568-577.

KÜHNER, R. 1977. Variation of nuclear behaviour in the Homobasidiomycetes. Trans. Br. Mycol. Soc., 68, 1-16.

LANQUETIN, P. AND BOIDIN, J. 1983. Obtention de mycéliums et de fructifications hybrides entre Dichostereum durum et D. sordulentum. Cryptogamie, Mycologie, 4, 375-402 (in French). 
LEMKE, P. A. 1969. A reevaluation of homothallism, heterothallism and the species concept in Sistotrema brinkmannii. Mycologia, 61, 57-76.

MACRAE, R. 1967. Pairing incompatibility and other distinctions among Hirschoporus (Polyporus) abietinus, $\mathrm{H}$. fuscoviolaceus and H. larcinus. Can. J. Bot., 45, 1371-1398.

MARTIN, K. J. AND GILBERTSON, R. L. 1973. The mating systems and some other cultural aspects of Veluticeps berkeleyi. Mycologia, 65, 548-557.

MAY, B., HENLEY, K. J., FISHER, C. G. AND ROYSE, D. J. 1988. Linkage relationships of 19 allozyme encoding loci within the commercial mushroom genus Pleurotus. Genome, 30 , 888-895.

MOORE, R. T. 1985. Mating type factors in Pleurotus cystidiosus. Trans. Br. Mycol. Soc., 85, 354-358.

PARAG, Y. 1962. Mutations in the B incompatibility factor of Schizophyllum commune. Proc. Natl. Acad. Sci. U.S.A., 48, 743-750.

PURDY, L. H., TRESE, A. T. AND ARAGUNDi, J. A. 1983. Proof of pathogenicity of Crinipellis perniciosa to Theobroma cacao by using basidiospores produced in in vitro cultures. Rev. Theobroma (Brazil), 13, 157-163.

RAPER, J. R. 1966. Genetics of Sexuality in Higher Fungi. Roland Press, New York, U.S.A.

RAPER, J. R., BAXTER, M. G. AND MIDDLETON, R. B. 1958. The genetic structure of the incompatibility factors of Schizophyllum commune. Genetics, 44, 889-900.

RAPER, J. R. AND FLEXER, A. S. 1971. Mating systems and the evolution of the basidiomycetes. In: Petersen, R. H. (ed.) Evolution in the Higher Basidiomycetes, pp. 149-167. University of Tennessee Press, Knoxville, U.S.A.

RAYNER, A. D. M., COATES, D., AINSWORTH, A. M., ADAMS, T. J. H., WILLIAMS, E. N. D. AND TODD, N. K. 1984. The biological consequences of the individualistic mycelium. In: Jennings, D. H. and Rayner, A. D. M. (eds) Ecology and Physiology of the Fungal Mycelium, British Mycological Society Symposium, vol. 8, pp. 509-540. Cambridge University Press, London, U.K.

RAYNER, A. D. M. AND TURTON, M. N. 1982. Mycelial interactions and population structure in the genus Stereum: $S$. rugosum, S. sanguinolentum and $S$. rameale. Trans. Br. Mycol. Soc., 78, 483-493.

SCHAAP, T. AND SIMCHEN, G. 1971. Genetic control of recom- bination affecting mating factors in populations of Schizophyllum commune and its relation to inbreeding. Genetics, 68, 67-75.

SNIDER, P. J. AND RAPER, J. R. 1958. Nuclear migration in the basidiomycete Schizophyllum commune. Am. J. Bot., 45, 538-546.

STAMBERG, J. AND KOLTIN, Y. 1973. The organisation of the incompatibility factors in the higher fungi: the effect of symmetry on breeding. Heredity, 30, 15-26.

STEPHENSON, N. A. AND GOODAY, G. w. 1984. Nuclear numbers in the stipe cells of Coprinus cinereus. Trans. Br. Mycol. Soc., 82, 531-534.

SUAREZ, C. 1977. Growth of Crinipellis perniciosa (Stahel) Singer in vivo and in vitro. Ph.D. Thesis, University of London.

TAKemaru, T. 1961. Genetic studies on fungi. X. The mating system in Hymenomycetes and its genetical mechanism. Biol. J. Okayama Univ., 7, 133-211.

THOROLD, C. A. 1975. Diseases of Cocoa. Clarendon Press, Oxford, U.K.

ULLRICH, R. C. AND ANDERSON, J. B. 1978. Sex and diploidy in Armillaria mellea. Exp. Mycol., 2, 119-129.

ULLRICH, R. C. AND RAPER, J. R. 1975. Primary homothallism relation to heterothallism in regulation of sexual morphogenesis in Sistotrema brinkmannii. Genetics, 80, 311-321.

WHEELER, B. E. J. 1985. The growth of Crinipellis perniciosa in living and dead cocoa tissue. In: Moore, D., Casselton, L. A., Wood, D. A. and Frankland, J. C. (eds) Developmental Biology of Higher Fungi, British Mycological Society Symposium, Vol. 10, pp. 103-116. Cambridge University Press, London, U.K.

WHEELER, B. E. J. AND MEPSTED, R. 1982. Pathogenic races of Crinipellis perniciosa. Proceedings of the Eighth International Cocoa Research Conference, 1981, Cartagena, Colombia, pp. 365-370. Lagos, Nigeria: Cocoa Producers Alliance.

WHEELER, B. E. J. AND MEPSTED, R. 1984. Pathogenic races of Crinipellis perniciosa (Stahel) Singer, the causal fungus of witches' broom of cocoa (Theobroma cacao L.) Final Report of the Cocoa, Confectionery and Chocolate Alliance, March 1984, Imperial College, London.

WHITEHOUSE, H. L. K. 1949. Multiple allelomorph heterothallism in the fungi. New Phytologist, 48, 212-244. 